\title{
The Application to Evaluate Worship Location Based on Geospatial Analysis: Case of Indonesia
}

\author{
Cahyo Crysdian \\ Jurusan Teknik Informatika, Universitas Islam Negeri Maliki Malang, Malang, Indonesia \\ Email: crysdian@yahoo.com
}

Received July 13, 2013; revised August 13, 2013; accepted August 20, 2013

Copyright (C) 2013 Cahyo Crysdian. This is an open access article distributed under the Creative Commons Attribution License, which permits unrestricted use, distribution, and reproduction in any medium, provided the original work is properly cited.

\begin{abstract}
The application of geospatial analysis is a need to respond to the increasing number of social conflicts caused by the existence of public places of worships (PPW) in Indonesia. This conflict eventually becomes endemic among Indonesian cross-cultural society. Even though the government has produced a regulation-like policy namely SKB 2006 to manage the establishment of PPW, its contribution to avoiding or reducing the conflicts is in question. Researchers notice that the policy is misused in some incidents to even trigger the conflict. It is due to the presence of people participation defined in SKB 2006 particularly to determine the legalization of PPW. Currently there is no exact foundation used by the government to precisely measure the status of PPW, hence the decision to permit or reject any proposal to establish PPW is determined by the acceptance of surrounding society which in many occasions becomes the cause of the conflict. Therefore the government needs to regain control over the existence of PPW since these types of buildings are public facilities used by people in cross-cultural society. The research is to provide accurate information regarding the existence of PPW and the impact of their presence using geospatial analysis. The objective is to analyze the interaction between PPW and its surrounding objects. The analysis is based on PPW coverage, overlapping and blank spot area. A case study has been conducted to analyze the existence of PPW at Cemorokandang village, a part of Malang city in the province of East Java. The application highlights the issue of overwhelming PPW in the location of analysis.
\end{abstract}

Keywords: Geospatial Analysis; Spatial Application; Worship Location

\section{Introduction}

Social conflicts due to the problem for establishing public places of worships (PPW) such as the mosques and the churches have been causing many incidents in Indonesia. Surveys conducted by some independent research group such as Setara Institute [1], Wahid Institute [2], and Center for Religious and Cross-cultural Study [3-6] reveal a phenomenon that the conflicts become endemic among Indonesian society. Statistics obtained from CRCS surveys for the last four years since 2008 to 2011 as depicted in Table 1, show that this conflict is untouchable and has even a stable growth from year to year. It seems that the efforts conducted by the government and many local organizations to promote peaceful society that lives in harmony are insignificant to stop or just to reduce this conflict. The authority has actually produced a regulation-like policy to manage the establishment of PPW namely SKB 2006 which stands for Surat Keputusan Bersama 2006/Collaborative Decision Letter 2006
[7]. The policy is the product of collaboration between the Ministry of Interior and the Ministry of Religion, and it has been admitted by all faith communities in Indonesia to become the only protocol to manage and to settle any dispute regarding the establishment of PPW. Although it has been prevailed for a half decade, its impact to reduce or even to stop the conflicts is in question since the number of incidents has increased drastically in the recent years as shown in Table 1. Therefore it is crucial to develop a new approach to dealing with the existence

Table 1. Number of incidents caused by PPW conflicts.

\begin{tabular}{ccccccccc}
\hline & \multicolumn{3}{c}{ Year 20XX } & \multicolumn{4}{c}{ Annual growth rate (\%) } \\
\cline { 2 - 8 } on PPW & 08 & 09 & 10 & 11 & $08 / 09$ & $09 / 10$ & $10 / 11$ \\
\hline $\begin{array}{c}\text { Number of } \\
\text { incidents }\end{array}$ & 14 & 18 & 39 & 36 & 28.57 & 116.67 & -7.69 \\
\hline
\end{tabular}

Data sources: CRCS Annual Report 2008, 2009, 2010, 2011. 
and establishment of PPW in order to deliver an objective perspective on this issue.

As the only policy to govern the establishment of PPW, SKB 2006 states that the procedure to build PPW is started by fulfilling some prerequisites to obtain legal permit from the authority as depicted in Figure 1. This procedure states that the effort to build new PPW must be supported by at least 60 local residents and be exhibited at least 90 members of a faith group as the user of this facility. This condition is to obtain a letter of recommendation from government-based institution which is represented by the district office of the Ministry of Religion (Kantor Kementerian Agama/KEMENAG), and a recommendation from the community-based organization which is represented by the Forum of Faith Community Members (Forum Kerukunan Umat Beragama/FKUB). After obtaining letters of recommendation from both KEMENAG and FKUB, a proposal is then submitted to the local authority to obtain a permit to establish a new PPW. From this point, the legal status of new PPW has been acknowledged.

Meanwhile according to the survey of CRCS from 2008 to 2011, the causes of PPW conflicts are varied as active PPW was forced to close by a group of local residents, the permit of PPW was withdrawn by local authority, the owner of the building where PPW operates changed the function of the building for commercial businesses, and even illegal destruction of PPW facilities was done by some religious fanatics. All of these incidents have commonly been assessed by using SKB 2006 regarding their legal aspects and whether the parties involved in the conflict had conducted appropriate or inappropriate action. An example of this practice can be mentioned as follow. In the incident of PPW at Bogor town which is located about $60 \mathrm{~km}$ to the south of Jakarta, a group of local residents launched a demonstration to protest the establishment of a new PPW. They claimed that the permit to establish PPW was not valid since the documents describing the acceptance from at least 60 local residents were fake as admitted by PPW management in front of legal investigating officer. However, later in the court PPW management stated that they were forced to admit the existence of fake document by local faith group involved in the conflict [6]. Hence, in this case, the truth became unclear and the case has to take a long journey on the court to validate any evident on the legal basis, while the necessity of local residents to worship has to wait until all of this process settled in an unpredictable time. This example shows the difficulty to employ SKB 2006 in practice due to subjective judgment from each party involved in this conflict. To date, a dozens of similar cases have been reported without any clue when thorough solution can be achieved [1,2]. These facts indicate the complexity of employing SKB 2006

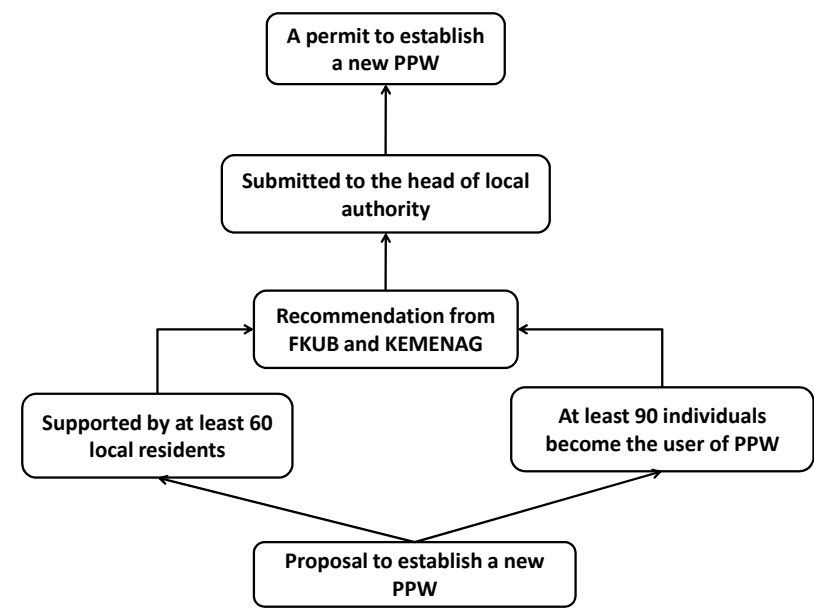

Figure 1. Procedure to legalize PPW based on SKB 2006.

particularly in the point of involving people participation to determine the status of PPW on the legal basis.

Moreover, if the incidents based on PPW conflict are scrutinized, it is apparent that the demand to establish PPW in Indonesia is very high and becomes the obligation of the authority to fulfill it. Since religious life is a sensitive issue among Indonesian cross-cultural society due to the existence of uncontrolled religious fanatics [8], a top-down approach should be employed to avoid subjective judgment from local residents to determine the legal status of PPW. This strategy requires the support from spatial data system to achieve accurate decision on establishing PPW among a cross-cultural society. Thus developing correct spatial technology becomes a vital approach towards settling PPW conflict in an objective manner.

\section{Related Works}

The works to analyze and to manage PPW have actually been started from centuries ago. It is shown by a literature found from Al-Quran 9:107-108 which stated that there were the existence of mosques intended to destroy muslim society, and hence it prevented people from conducting worship in those buildings [9]. The literature was revealed during the life of Prophet Muhammad from 570-632 AD. Although the works have been started from a long time ago, nowadays only few literatures can be found scrutinizing the existence of PPW in a quantitative manner. The work of Hoernig [10] even though presenting a comprehensive evaluation on PPW in the suburbs, however it is based on qualitative analysis. This approach is widely known suffered from a degree of subjectivity due to data constraint. Therefore the result would most likely be varied for different research location. Other works which follow Hoernig to evaluate PPW such as conducted by MSHL [11] and Oakville [12] failed to deliver generic information related to the phenomenon 
shown by each criterion. They are eventually uncertain on which location PPW need to be established and how to satisfy the need of faith communities.

The only quantitative analysis shown in this field is exhibited by the efforts of Ayhan and Cubukcu [13] and Srirangam and Forsyth [14]. Here Ayhan and Cubukcu study the influence of mosques to the development of surrounding area in Turkey using spatial distribution of mosques and a set of statistical methods. While Srirangam and Forsyth study the relationship between Hindu temples and retail activities in Chennai city India. They employ a set of tools namely space syntax, land use and figure-ground study to conduct spatial analysis on the existence of individual temple related to its surrounding. The study delivers a set of typologies exhibiting the influence of each temple to surrounding shopping complex, streets and city landmarks. However since the existence of PPW is in fact not evenly distributed as noted by MSHL [11], it is important to dig up the cause why some area contain more PPW than others and quantitatively measure the effect of this phenomenon. And the fact that PPW is a sensitive issue and has become an area of considerable land use conflict [10], hence it is not surprising that the statistics of social conflicts due to PPW in Indonesia as documented by CRCS [3-6] is very high. Malaysia has started to manage this problem by defining and classifying PPW based on the size and their coverage to accommodate worshippers [15], such as Masjid Negara is a national mosque, Masjid Negeri for state mosques, Masjid Daerah for common public mosques, Masjid Kampung is a mosque resided in every village, and Surau to accommodate worshippers at a small area such as in organizational offices. Indonesia actually employs a similar PPW classification as Malaysia. Although there is no documentaries or any literatures assigned to classify PPW, it is apparent that Mosque Istiqlal is a national mosque as addressed by some literature $[16,17]$ and there exist of a set of provincial mosques which are called Masjid Raya that can be regarded as state mosque in Malaysia. However with the existence of dense population inside the country particularly in Java island, the number of worshippers far beyond maximum space provided by the organized PPW. This condition triggers the development of many unorganized PPW which in many occasions have been causing social conflicts.

\section{System Development}

Developing spatial application to analyze the influence of PPW to its surrounding apparently leads to the need of measuring the existence of each PPW as the subject of conflict related to the existence of other spatial objects such as human population, public facilities, and other PPW within a certain area of investigation. Here 3D city model become the correct technology to rely on since it is capable to present spatial information of a specific object using 3D visualization. Although most efforts on developing 3D city model such as Jutraz et al. [18] and Pylvanainen et al. [19] utilize the technology to support only visualization purposes, however in this research the usage of $3 \mathrm{D}$ city model is extended to measure the influence of PPW to its surrounding environment using geospatial analysis. The purpose of the analysis is to compute the interaction between PPW with other objects existed in particular area of investigation. To settle this task, it is important to define to what extend the implementation of 3D city model is desired in order to support geospatial analysis in an efficient manner. Therefore it is vital to recognize what data are available and whose parties become the user of the implemented system as described in the following sub-sections.

\subsection{Model of Earth Surface}

Visualization of earth surface become the foundation to develop 3D city model, therefore the availability of accurate data is demanded in the acquisition stage. Here, a set of elevation data obtained from Digital Elevation Model (DEM) is utilized to develop spatial model of earth surface. Since data set from Shuttle Radar Topographic Mission (SRTM) has been recognized as the most accurate DEM available in Internet [20,21], thus it is used as the base to develop 3D model. However this approach is not obstacle free, there are at least two main issues resisting the application of SRTM i.e. elevation data set contain blank data value and carry low spatial resolution at approximately $90 \mathrm{~m}$ for non US region. Although the problems of SRTM data set have been addressed by researchers years ago [22,23], however it is worth to briefly describe the approach to counter them. Hence system development can be presented in a comprehensive manner. The first problem i.e. the existence of blank data is caused by unsuccessful acquisition of elevation data particularly for the area with a steep slope, thus it become the classical problem of SRTM data set. This problem is easy to recognize since the area which contain blank data would carry much higher value i.e. 32,768 than normal elevation data. The highest place on earth namely Mount Everest has elevation only about 8848 meters above sea level. Once the blank data is detected, then interpolation is employed to replace it with a predicted elevation value computed from the elevations of its neighboring points.

Second problem i.e. low spatial resolution at approximately $90 \mathrm{~m}$ is actually not the problem of SRTM. However it becomes an obstacle when development requires much higher resolution than SRTM could provide. It is due to the existence of spatial objects of interest that have smaller size than SRTM resolution such as the house and the building, in which the width of these ob- 
jects is in the range of few meters to maximum 50 meters. Again interpolation is employed to achieve higher resolution of elevation data set. Although detail contour of land surface is mostly lost due this approach, however it is still capable of delivering the approximate elevation value of the location of interest besides its main function to determine the exact point where the object sits on earth.

\subsection{Model of Road Network}

Information of road network is important to present the accessibility of PPW to local population living in the visualized region. Data of road network is mainly obtained by digitizing satellite photograph. It is worth to note that satellite photograph is the only media found showing a complete network of road in the location being analyzed. Therefore it is utilized to become the only input to develop visualization of road network. This decision is considered as a cost-effective approach since satellite photograph is easy to find either from Internet or other data banks such as from local agency of development planning. To cope with low spatial literacy of the personnel who handle data acquisition, a widely used third party application such as MS Excel can be employed to record the required information as depicted in Table 2.

Model of road network is then developed by drawing a set of rectangular shapes based on the recorded data in Table 2, and then lying them on the model of earth surface. Here the edges of each shape representing the road are defined as a 5-tuple (LAS, LOS, LAE, LOE, RW) which consists of two ordered-pairs i.e. (LAS, LOS) and ( $L A E, L O E$ ) that represent geographic coordinate of the starting and the ending point of a road in latitude and longitude coordinate respectively. Meanwhile a constant $R W$ denotes a road width. Two simple assumptions are applied in this approach. First, it is assumed that the width of a road is static, and second it is assumed that a road always creates a straight line from the beginning to the end of the road. Thus to cope with the road that has a bending direction and changing widths, the model is developed by dividing and recording the road into some segments and then the model is built independently for each segment. This approach greatly facilitates the visualization of any road condition using a straight line and a static width.

\subsection{Model of Building}

Actual cities condition in Indonesia consist of many different type of buildings such as shopping complex, block offices, hotel, etc. However since the commitment of this project is to analyze the existence of only PPW, hence only PPW buildings are developed to become 3D model.
Table 2. Table to record data of road network.

\begin{tabular}{cccccc}
\hline $\begin{array}{c}\text { Road } \\
\text { name }\end{array}$ & $\begin{array}{c}\text { Latt } \\
\text { start }\end{array}$ & $\begin{array}{c}\text { Long } \\
\text { start }\end{array}$ & $\begin{array}{c}\text { Latt } \\
\text { end }\end{array}$ & Long end & $\begin{array}{c}\text { Road } \\
\text { width }\end{array}$ \\
\hline $\begin{array}{c}\text { Rd. } \\
\text { Ahmad } \\
\text { Yani }\end{array}$ & -7.934988 & 112.645464 & -7.937828 & 112.643866 & 24 \\
$\begin{array}{c}\text { Rd. Letjen } \\
\text { Sutoyo } \\
\text { Rd. }\end{array}$ & -7.960414 & 112.636957 & -7.964541 & 112.634973 & 24 \\
$\begin{array}{c}\text { Jagung } \\
\text { Suprapto }\end{array}$ & -7.964541 & 112.634973 & -7.969045 & 112.632508 & 24 \\
$\ldots$ & $\ldots$ & $\ldots$ & $\ldots$ & $\ldots$ & $\ldots$ \\
\hline
\end{tabular}

According to Indonesia Government Regulation No 28 Year 2002 about building construction [24] currently there are six types of PPW building in Indonesia namely Masjid (Mosque) for Islam, Church for Christian and Catholic, Pura (Hinduism temple), Vihara (Buddhism temple), and Litang or Kelenteng (Khonghucu temple). This setting is accommodated by developing 3D model for each PPW building using polygonal modeling approach. The idea is to visualize the common form of PPW building from each religion using a set of polygons. Therefore it is required to choose common presentation of PPW building from each religion prior to develop 3D model. Detail steps to build 3D model of PPW building are listed as follows:

- Identify common form of PPW building from each religion.

- List every polygon required to represent each PPW building.

- Assemble a set of polygons to become 3D model of PPW building.

Next step is to locate PPW model on the model of earth surface based on the geographical coordinate of each building. It is necessary to collect data of the location of each PPW building found in the field, and to put them in a simple structure as shown in Table 3 to facilitate $3 \mathrm{D}$ model integration.

\subsection{Model of Population}

Visualization of local population in the area of interest is vital to present the impact of PPW to its surrounding particularly due to the nature of PPW as a public facility for worship activities. Thus it is important to create the model of population to enable the analysis of the interaction between PPW and local residents. Common approach to visualize local population usually is accomplished by developing model of each house such as conducted by Burch et al. [25]. This approach however is difficult to cope with fast changing data of residential housing in the third world since the growth of settlements are very high and less organized. It is widely recognized that semi permanent building used for low standard 
Table 3. Table to record data of PPW building.

\begin{tabular}{|c|c|c|c|c|c|}
\hline PPW ID & PPW name & Type & Dimension & Latitude & Longitude \\
\hline 1 & Musholla Santana & Mushola & Small & -7.992406 & 112.682399 \\
\hline 2 & Masjid Omaview & Mouse & Medium & -7.988063 & 112.678945 \\
\hline 3 & Musholla Omaview & Mushola & Small & -7.988091 & 112.682814 \\
\hline 4 & Masjid Buring & Mouse & Medium & -7.992236 & 112.678475 \\
\hline 5 & Masjid Baran Tempuran & Mouse & Medium & -8.005497 & 112.677774 \\
\hline 6 & Musholla Baran Tempuran & Mushola & Small & -8.005266 & 112.676585 \\
\hline$\cdots$ & $\cdots$ & $\ldots$ & $\ldots$ & $\ldots$ & $\ldots$ \\
\hline
\end{tabular}

housing can be built or removed overnight. Therefore it is important to choose more static data yet adequately represent the distribution of local residents. Rather than recording every house found in the location, it is preferred to record the block of residential housings since these types of data are more static and would not change easily. Furthermore the model of population can easily be implemented using a set of polygons which are drawn on the top of earth surface model.

\subsection{Geospatial Analysis}

Development of geospatial analysis aims to disclose the influence of PPW to its surrounding and highlight any potential issue causing social conflict. Prior to developing geospatial analysis, the conditions of PPW and its surrounding are visualized in 3D based on the previous developed model. In this stage, the model of earth surface become the ground of three other models described in the previous sub section i.e. the reference point where those models are located in the visualization frame is based on the latitude, longitude, and altitude value of earth surface model. Geospatial analysis is then developed by formulating three basic parameters of PPW as a public facility i.e. the coverage, overlapping and the blank spot in the area of analysis. The former is defined as the capacity of PPW to accommodate worshippers. Since the fact shows that local residents become major worshippers of PPW, thus definition of coverage becomes how wide PPW is capable of covering the settlement of local residents with respect to the size of PPW and the number of residents living in each residential housing complex that are willing to worship. A field study [26] has been conducted to deliver quantitative measurements on this issue as given in Table 4.

With the assumption that PPW covers the living area of worshippers in all direction, the coverage of each PPW has a form of a circle fulfilling the area $\pi r^{2}$ in which $r$ is the radius of coverage. Thus total area covered by $k$ number of PPW is derived using Equation (1).

$$
A_{C}=\sum_{n=1}^{k} \pi r_{n}^{2}
$$

However it would be difficult to employ only Equation
Table 4. PPW coverage.

\begin{tabular}{ccc}
\hline Size & Number of worshippers & Radius of coverage \\
\hline Small & $<40$ & $100 \mathrm{~m}$ \\
Medium & $40-100$ & $500 \mathrm{~m}$ \\
Large & $>100$ & $1000 \mathrm{~m}$ \\
\hline
\end{tabular}

(1) to measure the real coverage of PPW since it requires no overlap among each PPW coverage which is almost impossible to found in reality. The facts even show that the condition of overlapping is spread out and can be found anywhere in the field. Thus it is important to measure the area of overlap between PPW coverage. However it is difficult to compute this area using geometry since there exist various scene of PPW coverage that can be regarded as overlap as shown in Figure 2. In this research set theory is employed to facilitate the formulation of overlap $O$ which is defined as the condition where at least two PPW coverage occupy the same area based on their geographic coordinate as stated in Equation (2). Here $L$ is a set of geographic coordinate representing the area of analysis, while $c_{m}$ and $c_{n}$ is the coverage of a single $m$-th and $n$-th PPW respectively. Hence using a predefined geographic resolution $q$ from the location of analysis, the area of overlap $A_{o}$ is obtained using Equation (3).

$$
\begin{gathered}
O=\left\{i \mid \forall i \in L, i \in\left(c_{m} \cap c_{n}\right), c_{m} \subset L, c_{n} \subset L, m \neq n\right\} \\
A_{O}=q^{2} \sum_{i=1}^{l} 1 \Leftrightarrow i \in O
\end{gathered}
$$

Equations (2) and (3) significantly change the computation to derive PPW coverage since there always exist a certain amount of overlapping in every location of analysis. Thus by considering the aspect of overlapping, the definition of PPW coverage $C$ become as stated in Equation (4), while real area of coverage from $k$ number of PPW is obtained using Equation (5).

$$
\begin{aligned}
& C=\bigcup_{m=1}^{k} c_{m} \Leftrightarrow c_{m} \subset L \\
& A_{R C}=q^{2} \sum_{i=1}^{l} 1 \Leftrightarrow i \in C
\end{aligned}
$$

Meanwhile, blank spot is defined as the area with no 

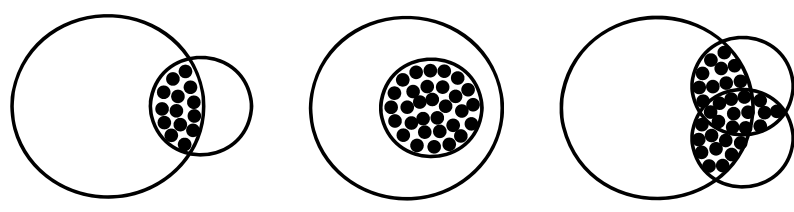

Figure 2. Various scenes of overlapping between PPW coverage.

single coverage of PPW can be found in the location of analysis as formulated in Equation (6). Based on the assumption that worshippers can live in any part of the location i.e. there is no definition of resident housing, the area of blank spot $A_{B}$ can simply be obtained by deducting total area of analysis $A_{L}$ by the area of real PPW coverage as stated in Equation (7). This approach is suitable to analyze the existence of PPW in the location with dense population such as the center of a city, where it is almost impossible to separate residential housing with another land use.

$$
\begin{gathered}
B=\left\{i \mid \forall i \in L, i \notin C_{m}, c_{m} \subset L, m=1, \cdots, k\right\} \\
A_{B}=A_{L}-A_{R C}
\end{gathered}
$$

However if the existence of residential housing can be localized and is considered in the analysis, then the definition of blank spot would slightly change to become as stated in Equation (8). Here the existence of residential housing is represented by a matrix $H$ which consists of a set of housing block $h_{1}, \cdots, h_{q} \subset H$ with $h_{s} \cap h_{t}=\phi$ in which $s \neq t, s=1, \cdots, q, t=1, \cdots, q$. Equation (8) highlights the existence of blank spot only on the area where local residents live in.

$$
\begin{gathered}
B=\left\{i \mid \forall i \in L, i \in H, i \notin c_{m}, H \subset L,\right. \\
\left.c_{m} \subset L, m=1, \cdots, k\right\}
\end{gathered}
$$

\section{Field Study}

A field study had been conducted to analyze the existence of muslim PPW at Cemorokandang village, an eastern boundary of Malang town at East Java province. This location is preferred to become the study area due to the existence of dense PPW among scattered residential housing block. Currently the village has a total area of approximately about $4 \mathrm{~km}^{2}$ and becomes the host of about twelve housing blocks, while the number of recognized PPW in the entire district is about 18 buildings. It is noteworthy to underline that only muslim PPW can be found in this location, hence the existence of PPW from other religion is not observed. Result of visualizing the spread of housing block as well as the existence of PPW is depicted in Figure 3. Meanwhile result of visualizing PPW coverage in the study area is shown in Figure 4. Based on Figure 4, a set of parameters defined in Sub Section 3.5 are computed and presented in Figure 5.

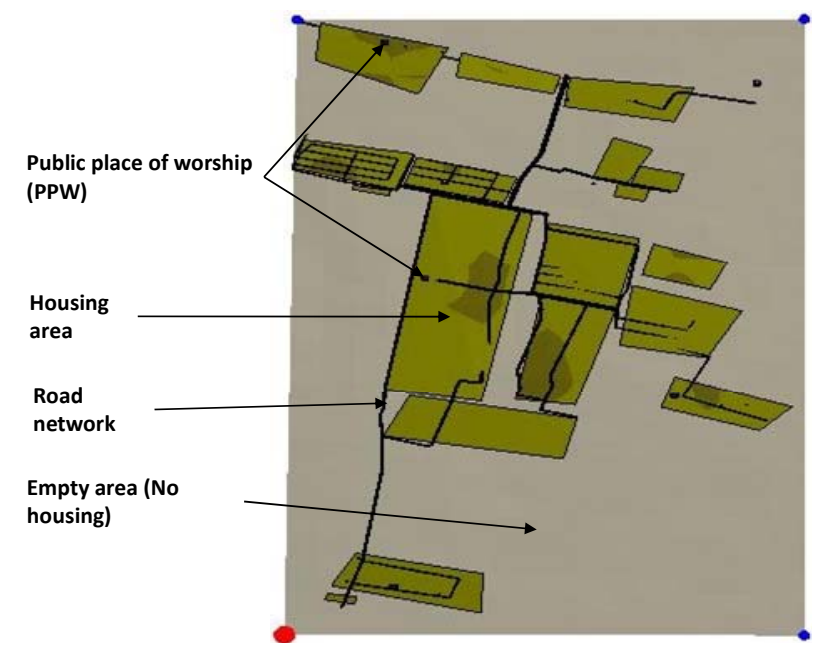

(a)

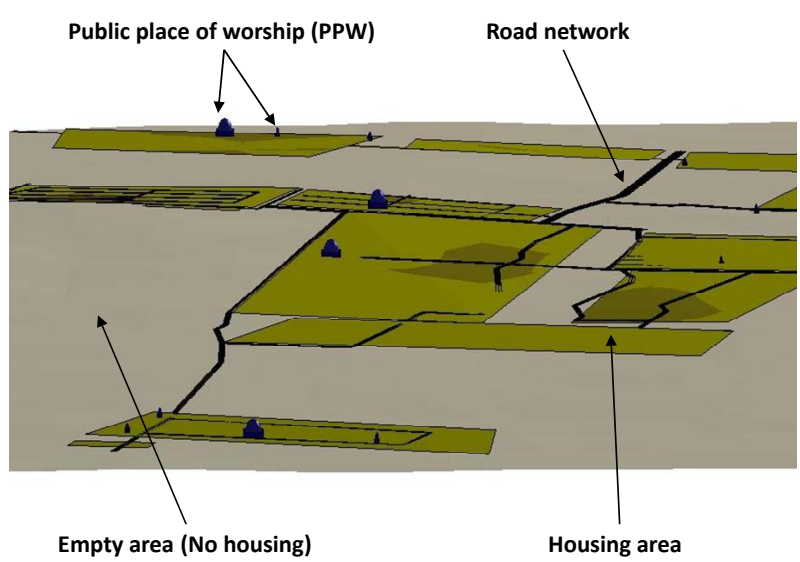

(b)

Figure 3. The spread of housing blocks and the existence of PPW in the study area. (a) Top view, (b) View from a certain angle.



Figure 4. Visualization of PPW coverage in the study area.

From these graphs, it is known that the existence of residential housings is not dominance in the location of study 
which occupies only $25 \%$ of total area as shown in Figure 5(a). Meanwhile the coverage of PPW has reached $72 \%$ of total area as shown in Figure 5(b), in which 27\% of this coverage overlaps with its other as in Figure 5(c). However if the coverage is compared against the area of housing, only $29 \%$ of PPW coverage is in the housing area while the other $71 \%$ covers nothing as shown in Figure 5(d). Only $84 \%$ of housing area is covered by PPW while the rest $16 \%$ of housing become the blank spot as shown in Figure 5(e). From $84 \%$ of the area of housing which is covered by PPW, $40 \%$ of them is covered by more than one PPW as shown in Figure 5(f). This fact shows excessive number of PPW existed in certain area of residential housing $(40 \%)$, while on the other hand $16 \%$ of housing area is left blank spot.

Further analysis based on the coverage of PPW found in the field are presented in Figures 6(a) and (b) respectively. These figures show the following facts:

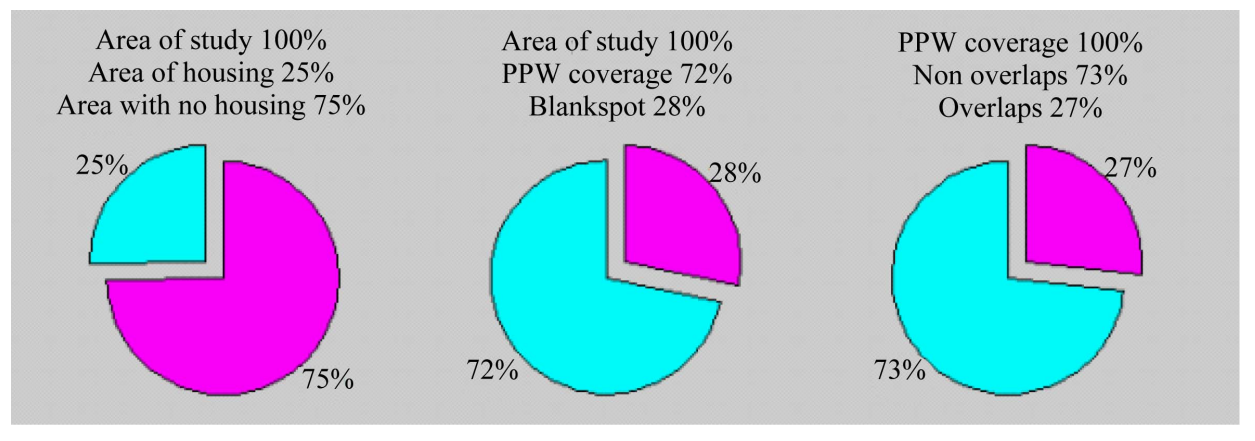

(a)

(b)

(c)

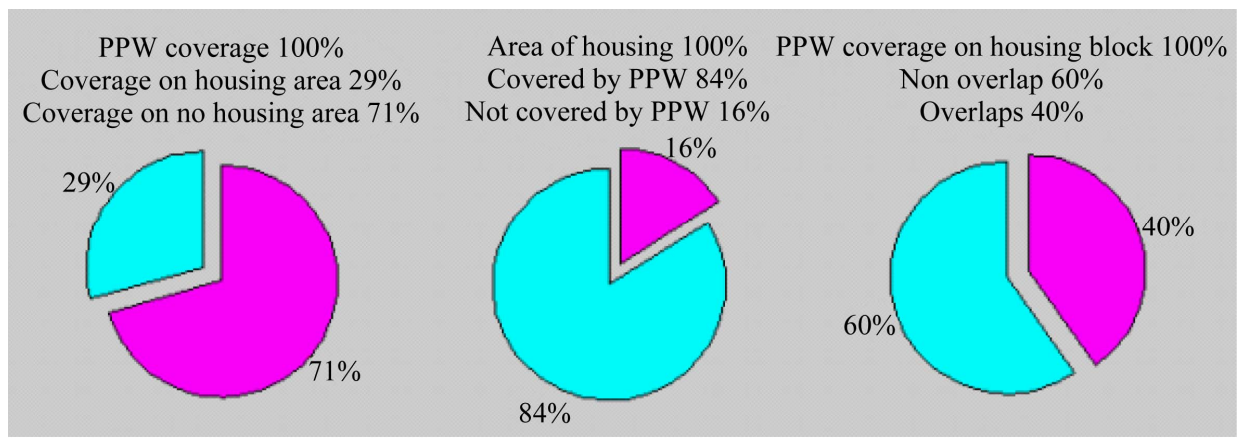

(d)

(e)

(f)

Figure 5. Performance of PPW obtained from field study.



(a)

(b)

Figure 6. Result of field study. 
- The area of coverage from all PPW obtained using Equation (1) consists of 59\% real coverage delivered by Equation (5) and the rest $41 \%$ error as shown in Figure 6(a). Here the error is composed by the existence of overlapping among PPW coverage and the existence of coverage which exceeds the boundary of analysis. The last error is due to the placement of PPW that is too close to the edge of the area of analysis. Even though the error facilitates neighboring area to have worship facility, however it also shows less contribution of PPW coverage to accommodate worshippers in the area where PPW exist.

- The majority of PPW coverage is found in the area of no housing (empty area) that reach $51 \%$ from total area of study, in which it consists of $40 \%$ coverage with no overlaps and $11 \%$ with overlaps. This condition is shown in Figure 6(b).

- Figure 6(b) also shows that from $25 \%$ area of housing found in the location, only $21 \%$ is covered by PPW while the rest $4 \%$ is left blank spot.

Based on the above points, it is apparent that the effectiveness of PPW coverage to accommodate worshippers in the location of study is relatively low. This condition is proved by the fact that only $59 \%$ of real PPW coverage can be established from $100 \%$ coverage should be constructed by all PPW found in the location. It means there exist a total of $41 \%$ coverage error. Meanwhile PPW covers empty area with no residential housing as much as $51 \%$ from $100 \%$ total area of analysis, and on the other hand it left $4 \%$ of housing area as blank spot. Thus the existing PPW wastes its coverage to cover nothing rather than removing blank spot contained in residential housing.

The study reveals that overwhelming PPW have been built in the area of study since the ideal coverage i.e. total area of PPW coverage without considering overlapping is bigger than the whole area of study. However they fail to cover all area of residential housing as shown in Figure 5(e) even though residential housing exist in only the small part of total area as shown in Figure 5(a). This phenomenon shows that the establishment of PPW wastes a lot of resources. This phenomenon shows many PPW were built without any awareness that the developed PPW may cover nothing. This fact discloses low concern on developing proper PPW coverage i.e. whether the coverage really reduces the blank spot on the housing area and minimizes the possibility of overlapping among PPW.

\section{Conclusion}

Objective perspective can be delivered by geospatial analysis to evaluate the existence of PPW as public facility. The analysis enables the measurement of PPW coverage to accommodate worship activities. Moreover it can be utilized to compute the influence of PPW to other objects existing in the area of study such as a set of residential housings and other neighbouring PPW. The objective of the research is to compute three basic parameters derived from the presence of PPW namely the coverage of PPW, overlapping between PPW coverage, and the existence of blank spot area. Computation on these parameters is conducted on three different domains i.e. on the whole area of study, on the housing area, and on the area of PPW coverage. Result of analysis quantitatively discloses the performance of PPW to become the facility to worship in terms of its coverage. The analysis leads to present the real condition of PPW, for example, whether a group of PPW on a particular area is properly developed, suffering from lack of planning or still requiring more building to extend their coverage. It is worth to note that the use of cost-efficient 3D city model greatly facilitates the implementation of the system since it saves the need of resources and simplifies the procedure to develop 3D model. Rather than developing a complex 3D city model that consists of complicated objects, cost-efficient approach simplifies the content of 3D city model by summarizing the objects of city environment into a simple model such as individual building house replaced by the model of housing block. Therefore it successfully reduces resources to be deployed in the implementation stage and requires only simple procedure yet it is enough to conduct geospatial analysis.

\section{REFERENCES}

[1] SETARA, "Report on Freedom of Religion and Belief in 2012," 2012. http://www.setara-institute.org

[2] WAHID, "Laporan Akhir Tahun Kebebasan Beragama dan Intoleransi," 2012. http://www.wahidinstitute.org

[3] CRCS, "Laporan Tahunan Kehidupan Keagamaan Tahun," 2008. http://crcs.ugm.ac.id

[4] CRCS, "Annual Report on Religious Life in Indonesia," 2009. http://crcs.ugm.ac.id

[5] CRCS, "Laporan Tahunan Kehidupan Keagamaan Tahun," 2010. http://crcs.ugm.ac.id

[6] CRCS, "Laporan Tahunan Kehidupan Keagamaan Tahun," 2011. http://crcs.ugm.ac.id

[7] SKB, "Pedoman Pelaksanaan Tugas Kepala Daerah/ Wakil Kepala Daerah Dalam Pemeliharaan Kerukunan Umat Beragama, Pemberdayaan Forum Kerukunan Umat Beragama, Dan Pendirian Rumah Ibadat," Peraturan Bersama Menteri Agama Dan Menteri Dalam Negeri Nomor 9 Tahun 2006 dan Nomor 8 Tahun 2006.

[8] SETARA, "The Faces of Islam 'Defenders'," Pustaka Masyarakat Setara, 2010.

[9] M. M. Pickthall, "The Meaning of the Glorious Qur'an," Islamic Book Trust, Kuala Lumpur, 2001.

[10] H. J. Hoernig, "Worship in the Suburbs: The Development Experience of Recent Immigrant Religious Com- 
munities," PhD Thesis, University of Waterloo, 2006.

[11] MSHL, "Places of Worship Policy Review," Prepared for the City of Brampton for Discussion Purposes, 2008.

[12] Oakville, "Town of Oakville: Places of Worship Land Use Study," Town of Oakville Planning Services Department, 2011.

[13] I. Ayhan and K. M. Cubukcu, "Explaining Historical Urban Development Using the Locations of Mosques: A GIS/Spatial Statistics-Based Approach," Applied Geography, Vol. 30, No. 2, 2010, pp. 229-238.

[14] S. Srirangam and W. Forsyth, "Culture and Commerce of Chennay City-A Spatial Analysis of the Relationship between Temples and Retail Activity," Proceedings of 8th International Space Syntax Symposium, Santiago de Chile: PUC, 2012.

[15] Malaysia, "Garis Panduan Perancangan Tempat Ibadat Islam. Jabatan Perancangan Bandar dan Desa Semenanjung Malaysia," Kementerian Perumahan dan Kerajaan Tempatan Malaysia, 2002.

[16] I. Hasan, "Architecture and the Politics of Identity in Indonesia: A Study of the Cultural History of Aceh," $\mathrm{PhD}$ Thesis, University of Adelaide, 2009.

[17] B. A. Sukada, "The Architecture of Early Independence. Indonesian Heritage: Architecture," Archipelago Press, Singapore, 1996.

[18] A. Jutraz, A. Voigt and T. Zupanci, "3D City Model as Understandable Design Interfaces for lay Public," Journal of Society for Development of Teaching and Business Processes in New Net Environment in B\&H, Vol. 6, No. 4, 2011, p. 890.

[19] T. Pylvanainen, J. Berclaz, T. Korah, V. Hedau, M. Aanjaneya and R. Grzeszczuk, "3D City Modeling from Street Level Data for Augmented Reality Applications," Proceedings of 2012 Second Joint 3DIM/3DPVT Conference: 3D Imaging, Modeling, Processing, Visualization and Transmission, 2012.
[20] C. Huggel, D. Schneider, P. J. Miranda, H. D. Granados and A. Kaab, "Evaluation of ASTER and SRTM DEM Data for Lahar Modeling: A Case Study on Lahars from Popocatepetl Volcano, Mexico," Journal of Volcanology and Geothermal Research, Vol. 170, No. 1-2, 2008, pp. 99-110. http://dx.doi.org/10.1016/j.jvolgeores.2007.09.005

[21] E. Suwandana, K. Kawamura, Y. Sakuno, E. Kustiyanto and B. Raharjo, "Evaluation of ASTER GDEM2 in Comparison with GDEM1, SRTM DEM and Topographic Map Derived DEM Using Inundation Area Analysis and RTK-dGPS Data," Journal of Remote Sensing, Vol. 4, No. 8, 2012, pp. 2419-2431. http://dx.doi.org/10.3390/rs4082419

[22] C. Crysdian, "3D Visualization of Small Scale Spatial Object Based on Digital Elevation Model," Proceedings of 2nd International Conference on Distributed Frameworks and Application, Yogyakarta, 2010.

[23] T. G. Farr, P. A. Rosen, E. Caro, R. Crippen, R. Duren, S. Hensley, M. Kobrick, M. Paller, et al., "The Shuttle Radar Topography Mission," Reviews of Geophysics, Vol. 45, No. 2, 2007.

[24] Indonesia, "Undang-Undang Republik Indonesia Nomor 28 Tahun 2002 Tentang Bangunan Gedung," Lembaran Negara Republik Indonesia Tahun 2002 Nomor 134.

[25] S. Burch, A. Shaw, S. Sheppard and D. Flanders, "Climate Change Visualization: Using 3D Imagery of Local Places to Build Capacity and Inform Policy," State of Climate Visualization, CSPR Report, Vol. 4, 2009, pp. 65-73.

[26] C. Crysdian, "Penerapan Teknologi Informasi dan Komunikasi untuk Optimalisasi Proses Pelayanan Perijinan Pendirian Rumah Ibadat Menggunakan Analisa Data Spasial," Competitive Research Report, Research and Development Center (PUSLITBANG Kehidupan Keagamaan), Indonesia's Ministry of Religion, 2011. 